\title{
Ideologização da Violência no Capitalismo: Contribuições da \\ Psicologia da Libertação de Martín-Baró
}

Ideologization of Violence in Capitalism: Contributions of

Martín-Baró's Liberation Psychology

\section{Ideologization of Violence in Capitalism}

\author{
Karina Oliveira Martins', Fernando Lacerda Junior²
}

\begin{abstract}
Resumo
O presente trabalho apresenta as reflexões de Ignacio Martín-Baró sobre a ideologização da violência. Para tanto, divide-se em três partes. Na primeira parte, apresenta como Martín-Baró definiu violência, ideologia e desideologização destacando as principais ideias do autor sobre fenômenos que considerava fundamentais. Em seguida, são descritos sete processos psicossociais que demonstram a estreita relação entre ideologia e violência na perspectiva de MartínBaró: a) a difusão de uma concepção "neutra" e "moral" de violência; b) a conversão da violência em um problema técnico e administrativo, facilitando, assim, a proliferação de atos violentos; c) a desvalorização das vítimas dos atos violentos pela criação da imagem do "inimigo"; d) as consequências psicológicas da polarização social; e) a guerra psicológica; f) o fatalismo como processo psicossocial produzido pela violência estrutural; g) a desatenção seletiva. Por fim, o artigo discute limitações das propostas de Martín-Baró, assim como as contribuições de suas análises para a crítica da sociedade capitalista e para o fomento de práticas de transformação social.
\end{abstract}

Palavras-chave: Martin-Baró. Psicologia Social Crítica. Violência. Ideologia. Desideologização.

\begin{abstract}
This paper discusses the contributions of Martín-Baró to the critique of the ideologization of violence. First of all, the paper presents how Martín-Baró defined violence, ideology and de-ideologization highlighting his main ideas about those basic concepts. After that, seven psychosocial processes are described in order to describe the complex articulation between ideology and violence: (a) the diffusion of a "neutral" and "moral" conception of violence; (b) the conversion of violence into a technical and administrative issue, facilitating the proliferation of violent acts; (c) the devaluation of the victims through the creation of the "enemy"; (d) the psychological effects of social polarization; (e) psychological warfare; (f) fatalism as a psychosocial process produced by structural violence; (g) selective inattention. Finally, the article problematizes limitations of Martín-Baró's proposals and discusses the contributions of his analyses to the critique of capitalist society and to the promotion of practices of social transformation.
\end{abstract}

Keywords: Martin-Baró. Critical Social Psychology. Violence. Ideology. De-ideologization

\footnotetext{
${ }^{1}$ Universidade Federal de Goiás, Goiânia, Brasil. E-mail: kar1na.oliveira@hotmail.com

${ }^{2}$ Universidade Federal de Goiás, Goiânia, Brasil. E-mail: fernando_lac@yahoo.com.br
} 


\section{Introdução}

A sociedade capitalista é uma sociedade dividida em classes sociais, ou seja, há uma minoria privilegiada e uma maioria explorada e oprimida que apenas se mantém nessa situação por meio do uso permanente da violência (Netto \& Braz, 2006; Lessa, 2014). No entanto, o uso sistemático da violência demanda ocultamento e falseamento dos interesses envolvidos em seu uso. Para ser aceita socialmente, a violência deve aparecer como um instrumento, jamais como um fim em si mesmo. Assim, a violência necessária para a manutenção de uma ordem desigual deve ser legitimada e justificada para a maioria oprimida, enquanto a violência usada para romper e transformar essa ordem injusta é apresentada como baderna, negativa e injustificável.

O processo descrito anteriormente foi analisado criticamente por Ignacio Martín-Baró e o presente trabalho apresentará de forma sistemática como o autor estudou as possíveis relações entre violência e ideologia. Para tanto, destaca-se o conceito e a função da ideologia, assim como a relevância de seu estudo pela Psicologia, segundo Martín-Baró, para, então, se analisar a ideologização da violência.

O objetivo deste trabalho não é oferecer um estudo sistemático sobre a biografia e o significado teórico da obra de Martín-Baró (o que foi realizado por Blanco, 1998; de la Corte, 2001; Dobles, 2016) e nem explorar isoladamente o conceito de ideologia (tal como os trabalhos de Dantas, 2015; Sloan, 2015) ou o conceito de violência (ver: Blanco \& de la Corte, 2003; Martins \& Lacerda Jr., 2014). O foco aqui é contribuir para o aprofundamento dos estudos sobre a obra de Martín-Baró apresentando e problematizando como o autor explorou a dimensão ideológica da violência. A escolha da ideologia não foi aleatória, pois, para o autor, a finalidade da Psicologia Social é estudar, precisamente, o que há de ideológico na ação humana (Martín-Baró, 1985/2012) com a finalidade de contribuir para a superação da sociedade capitalista por meio da desideologização (Martín-Baró, 1980/2017; 1985/2017).

Dessa forma, o trabalho começa conceituando e descrevendo os aspectos mais relevantes dos estudos de Martín-Baró sobre a violência e a ideologia. Nesta primeira parte, pretende-se: demonstrar a historicidade da violência e a sua presença estruturante na sociedade capitalista; descrever a concepção de ideologia presente na obra de Martín-Baró e porque ela pode ser objeto da Psicologia Social; apontar como a desideologização é uma tarefa importante para uma Psicologia Social que assume a libertação como objetivo. Em seguida, destaca-se a relação entre ideologia e violência, problematizando, especialmente, o fundo ideológico da violência que se manifesta de diferentes maneiras: a) conversão da violência em problema moral e não histórico; b) conversão da violência em problema técnico; c) desvalorização das vítimas dos atos violentos; d) acirramento da polarização social; e) guerra psicológica; f) fatalismo; g) desatenção seletiva. Por fim, são oferecidas considerações finais sobre a relação entre ideologia e violência na obra de MartínBaró, destacando alguns limites e problemas nas análises do autor, assim como a importância da crítica da ideologia que é realizada em sua obra.

Os trabalhos analisados foram escolhidos a partir de uma sistematização 
anteriormente realizada por de la Corte (2001). Foram encontrados 21 textos que tratavam direta ou indiretamente sobre ideologia. A partir da leitura dos resumos, foram escolhidos nove trabalhos que tratavam de forma direta sobre a presença da ideologia na violência (Martín-Baró, 1976; 1985/2012; 1986; 1987a/2017; 1987b/2017; 1988a/2017; 1988b/2017; 1989).

\section{Violência}

Martín-Baró (1985/2012) define violência como o uso excessivo de força contra alguém ou algo, que não se restringe à força física e independe da intencionalidade de quem pratica a ação. Essa definição não apresenta uma conceituação sobre o que é força, o que torna o conceito muito amplo e, assim, pouco esclarecedor. Por isso, Martín-Baró (1988a/2017) destaca a necessidade de substantivar o conceito de violência apresentando as características da violência. São pontos fundamentais para a compreensão da violência: a) sua multiplicidade; b) seus componentes comuns; c) sua historicidade; d) sua instrumentalização por interesses de classe. Cada um deles serão descritos a seguir.

As diversas formas pelas quais a violência se manifesta, seus conteúdos e os distintos interesses efetivados por meio dela, convertem a multiplicidade em uma característica intrínseca. A violência se manifesta em diferentes níveis e formas: estrutural, interpessoal, educativo, pessoal, moral e simbólico. Essas múltiplas violências atuam em espiral: todo processo violento, ao ser efetivado, tende a se autonomizar em relação às suas causas imediatas, isto é, tende a produzir ainda mais violência, atuando de forma cíclica (Martín-Baró, 1985/2012).
Quatro dimensões são constitutivas de todo ato violento: estrutura formal, aspecto pessoal, contexto possibilitador e fundo ideológico. A estrutura formal revela o modo pelo qual a ação violenta se desenvolve, possibilitando identificar se a violência é usada de modo instrumental (é um meio para atingir um fim) ou como um fim em si mesmo (a chamada "violência gratuita"). O componente pessoal é a manifestação das características singulares do agente no ato violento por ele executado. Em certos contextos, o componente pessoal pode ser amenizado ou eliminado por meio da divisão da violência em uma série de atos técnicos executados sistemática e profissionalmente, tornando a execução da ação violenta uma questão técnica e impessoal. Esses atos de violência não se dão no vazio, há sempre um contexto imediato e circunstancial que a possibilita/facilita (portar armas, falta de iluminação em vias públicas, etc.) e um contexto social mediato marcado por valores e normas formais ou informais (cultura do estupro, homofobia, racismo, naturalização da violência intrafamiliar, etc.) - que a promove como uma forma de comportamento possível e necessário. Finalmente, o último componente expressa como a realidade em que se manifesta a violência é marcada por interesses de classes sociais que determinam a legitimidade das ações violentas. Trata-se, precisamente, do fundo ideológico da violência, isto é, as ações não são apenas justificadas e naturalizadas, mas podem ser vistas como nobres ou necessárias quando utilizadas em favor de uma classe ou um grupo social que, normalmente, se encontra em posição dominante na dialética opressor-oprimido (Martín-Baró, 1985/2012). 
Todos os elementos que compõem a violência são produtos da ação humana, isto é, não são produtos de forças externas e transcendentais e não são fatos naturais. São, portanto, elementos históricos. Todo ato e processo humano que existe na realidade atual, por ser histórico-social, pode ser modificado ou superado. Logo, se a violência é um ato humano, ela é, também, histórica e produto de relações sociais. Assim, os significados, produtos e a própria noção do que é violência se transformam de acordo com as transformações históricas das relações sociais (Martín-Baró, 1985/2012).

Sendo assim, não existe uma violência abstrata e universal, mas uma violência que se dá em um determinado contexto social em um determinado período histórico - o que demanda situar a violência em tempos e espaços específicos. Por isso, Martin-Baró (1985/2012; 1987a/2017; 1987b/2017) situou seu estudo sobre a violência em um contexto de lutas de classes sociais na sociedade capitalista, mais especificamente em uma sociedade capitalista dependente na América Latina: El Salvador. Justamente por ainda estarmos em uma sociedade capitalista dependente (Fernandes, 2009) é que os estudos de Martín-Baró sobre a violência são de grande atualidade para o contexto brasileiro.

A partir da análise da historicidade da violência e de suas particularidades no capitalismo, o autor afirma que a violência é estrutural, isto é, as estruturas sociais da sociedade capitalista funcionam por meio do emprego do uso excessivo da força, coagindo as pessoas a atuarem contra sua vontade (MartínBaró, 1985/2012).
A violência estrutural não se reduz a uma inadequada distribuição dos recursos disponíveis que impede a satisfação das necessidades básicas das maiorias; a violência estrutural supõe, além disso, o ordenamento dessa desigualdade opressiva, por meio de uma legislação que ampara os mecanismos de distribuição social da riqueza e estabelece uma força coercitiva para que eles sejam respeitados. O sistema fecha, assim, o ciclo de violência justificando e protegendo as estruturas que privilegiam a minoria à custa da maoria. (MartínBaró, 1985/2012, p. 406)

A violência estrutural configura-se a partir da cisão existente entre classes sociais com interesses antagônicos que resultam de suas relações com os meios de produção. Ainda que existam outras classes sociais, há duas que são fundamentais: a burguesia, detentora dos meios de produção e capaz de comprar a força de trabalho de trabalhadores e trabalhadoras que, por não possuírem meios de produção, necessitam vendê-la para sobreviver. A classe burguesa busca manter o seu poder por meio da exploração de trabalhadores e trabalhadoras. A classe trabalhadora busca sobreviver e combater ou evitar, direta ou indiretamente, a exploração. Esse antagonismo não é o único, mas estabelece os marcos fundamentais de existência na sociedade capitalista, por isso caracteriza-se como um conflito estrutural, isto é, que estrutura todas as outras relações sociais (Martín-Baró, 1985/2012; Netto \& Braz, 2006). Assim, há uma estrutura social que distribui os recursos materiais e simbólicos de forma desigual, criando relações 
de poder em que uma minoria privilegiada vive à custa de uma maioria oprimida - essa relação de exploração, em si, já é violência - o que só é possível por meio da coerção, isto é, pelo uso de força excessiva (sobre a noção de poder, ver Martín-Baró, 1989).

Entretanto, a violência no capitalismo não se limita a isso. A manutenção de uma estrutura desigual demanda a prevenção da rebelião por meio da repressão "legítima", ou seja, de um aparato repressivo, composto por elementos como a polícia e o sistema carcerário, amparado por legislação e valores que autorizam e valorizam a coerção violenta. Dessa maneira, a violência é, também, institucional, porque está presente nas diversas instituições sociais que conformam os aparatos estatal, jurídico, político e educacional. A violência não é apenas inerente ao sistema capitalista, mas estruturante das suas relações sociais na vida cotidiana das instituições (Martín-Baró, 1985/2012).

$$
\text { Ainda segundo Martín-Baró }
$$
(1985/2012), as relações estruturais norteiam os interesses individuais, independentemente do nível de consciência dos sujeitos em relação à pertença de classe, os valores e a própria organização das relações sociais. Afirmar que a violência é estrutural implica afirmar que ela é determinante em todas as outras relações sociais. Afirmar que há uma violência estrutural na sociedade capitalista significa, também, afirmar que ela determina as outras formas de violência.

Como a violência está presente na própria organização da sociedade, permeando todas as relações sociais, ela torna-se cotidiana e incide, diretamente, nos processos de subjetivação. Assim, certas formas de violência tornam-se aspectos comuns da realidade $\mathrm{e}$ podem, até mesmo, serem naturalizadas, a ponto de não serem percebidas como violência (MartínBaró, 1985/2012).

Para uma Psicologia Social que busca contribuir para a emancipação humana, é imprescindível desnaturalizar a violência, explicitar suas manifestações no cotidiano e o seu fundo ideológico. Mais ainda, se o objetivo é ir além das aparências e apreender e transformar as causas da violência, então é necessário explicitar os processos pelos quais ela é constituída, legitimada, naturalizada e ocultada. Com a noção de violência estrutural, percebe-se que a causa fundamental da violência na sociedade capitalista é a existência de conflitos e interesses antagônicos entre as classes sociais. Com o exposto, pode-se entender por que é necessário compreender a ideologia.

\section{Ideologia}

Para defender que a dimensão ideológica da ação é o objeto específico da Psicologia Social, Martín-Baró apresenta uma definição de ideologia que, inicialmente, é bastante ampla e, em seguida, é particularizada a partir da apropriação crítica das contribuições marxistas de Althusser. Assim, em termos amplos, a ideologia é produto da totalidade dos interesses sociais e é constituída por meio do sentido e da ação pessoal. A ideologia se manifesta em esquemas cognitivos e valorativos dos indivíduos. $\mathrm{Na}$ ideologia "as forças sociais se convertem em formas concretas de viver, pensar e sentir das pessoas, isto é, a objetividade social se converte em subjetividade individual e, ao atuar, a pessoa se realiza como sujeito social” (Martín-Baró, 1985/2012, p. 18). O autor aprofunda essa tese ao afirmar: 
A partir desta análise, podemos propor uma definição mais significativa de psicologia social como o estudo científico da ação como ideológica. Ao falar de ideológica, estamos expressando a ideia de influência ou relação interpessoal, de interface entre o pessoal e o social; mas também estamos afirmando que a ação é uma síntese de objetividade e subjetividade, de conhecimento e de valoração que não é necessariamente consciente, ou seja, a ação é marcada por certos conteúdos que são avaliados e historicamente relacionados com uma estrutura social. (Martín-Baró, 1985/2012, p. 17).

O momento ideológico é o momento de internalização das estruturas sociais. Estas tornam-se estruturas psíquicas. À Psicologia Social cabe compreender como a ideologia mediatiza as estruturas pessoal e social. Ou seja, compreender "a dupla realidade constituída pela pessoa que é realização e concretização de uma sociedade, e da sociedade tomada enquanto totalidade de pessoas e suas relações" (MartínBaró, 1985/2012, p. 16). O indivíduo é tanto resultado das forças sociais históricas, quanto produtor dessas forças, de modo que as estruturas psíquicas também constituem (sustentando ou modificando) a estrutura social.

Assim, o ideológico implica uma leitura da realidade "realizada desde determinados interesses sociais históricos, quer sejam os da própria classe, quer sejam dos interesses dominantes, quer seja uma mescla de uns e outros" (Martín-Baró, 1986, p. 74). A ideologia é uma interpelação da realidade que se dá por meio da vivência cotidiana que pode se opor aos interesses da própria classe ou convergir completamente. Sendo assim, toda ação é ideológica, pois é constituída por interesses determinados. Segundo o autor,

toda interpretação sobre o mundo é ideológica e, portanto, não há apenas ocultamento e justificação em determinadas ideologias, mas em todas. Para mim, o problema não reside aí, mas no grau e no caráter do ocultamento, da "falsa consciência". Mas me parece ingênuo achar que em uma sociedade imersa na luta de classes, tal como as nossas, há alguma abordagem sobre a realidade totalmente livre de interesses parciais, ou seja, uma leitura "acabada" ou "pura" da realidade. (Martín-Baró, 1986, p. 74)

Ao particularizar sua definição, destacando funções específicas da ideologia, o autor destaca a assimilação dos interesses da classe dominante pela classe dominada.

Afirmou-se que a ideologia cumpre uma série de funções: oferecer uma interpretação da realidade, fornecer esquemas práticos de ação, justificar a ordem social existente, legitimar essa ordem como válida para todos, isto é, naturalizar ao que é meramente histórico, exercer na prática a relação de domínio existente e reproduzir o sistema social estabelecido. (Martín-Baró, 1985/2012, p. 18) 
A classe dominada assume, como seus, os interesses e as interpretações da classe dominante. Contudo, não se trata de mera reprodução mecânica daquilo que é imposto pela classe dominante. A ideologia desenvolve-se por meio da prática cotidiana, por meio de experiências concretas vividas por grupos e indivíduos. Assim, a prática social precede a elaboração da visão de mundo, ao mesmo tempo em que é reflexo da complexidade de cada formação social em determinado momento histórico (Martín-Baró, 1986). Portanto, não se trata de conceber indivíduos como seres passivos que, meramente, internalizam as ideias dominantes e nem de uma total falsificação da realidade, pois a ideologia advém da prática cotidiana. A ideologia tem uma base material, expressa uma verdade parcial: a realidade que se afirma em sua imediaticidade e aparência ocultando, ao mesmo tempo, todas as possibilidades existentes que foram negadas para as classes dominadas.

Por meio da vivência cotidiana, a realidade aparenta ser imutável, pois os trabalhadores e as trabalhadoras na sua vida cotidiana não têm controle sobre o próprio tempo e a própria vida. Por isso, a ideologia serve como instrumento de dominação, pois mistifica, eterniza e naturaliza a realidade social existente. Contudo, como há uma relação dialética entre indivíduo e sociedade, entre produto e produtores das forças sociais, isto é, os sujeitos que, por meio da atuação no mundo, interpretam-no e transformam-no de diversas maneiras. Portanto, é possível, por meio de novas relações sociais, romper com a assimilação de interesses da classe dominante e desenvolver novas ideias, percepções e uma consciência de classe, isto é, a consciência dos interesses objetivos da classe social de pertença e da necessidade de orientar a atividade cotidiana, em prol da própria classe.

Ao afirmar que toda ação é ideológica, Martín-Baró entende que a ideologia se refere a qualquer conjunto de ideias e interesses. Assim, pode-se assumir que todas as interpretações sobre a realidade, na sociedade de classes, são igualmente "interessadas". Dessa forma, perde-se a especificidade que associa ideologia com o domínio da burguesia no plano simbólico e psíquico, o que, inclusive, contraria a proposta de desideologização apresentada pelo próprio Martín-Baró (1985/2017). Contudo, nota-se a ênfase do autor nos processos particulares da ideologia, especialmente na mediação entre as estruturas psíquicas e sociais e na assimilação dos interesses da classe dominante pela classe dominada. Isso é possível identificar nas discussões sobre desideologização.

\section{Desideologização}

Assumindo a concepção de ideologia como apropriação dos interesses da classe dominante pela classe dominada, cabe à Psicologia Social contribuir para a desideologização e, portanto, para o desenvolvimento da consciência de classe (Martín-Baró, 1985/2017).

À psicologia social cabe desmascarar os vínculos que ligam os atores sociais aos interesses de classe, revelar as mediações pelas quais as necessidades de uma classe social concreta se tornam imperativos interiorizados pelas pessoas, desarticular a trama de forças objetivadas em uma ordem social que manipula os sujeitos 
por meio de mecanismos de falsa consciência. (Martín-Baró, 1985/2012, p. 48)

Assim, desideologizar é o processo de desnaturalizar o senso comum e de efetivar a denúncia de obstáculos objetivos à superação das desigualdades sociais. Trata-se de uma das principais tarefas da Psicologia Social. Esta deve assumir a perspectiva do povo, aprofundar o estudo da estrutura da formação social em que os indivíduos estão inseridos e se comprometer com os processos pelos quais o povo busca ser sujeito de sua própria história (Martín-Baró, 1985/2017). É uma tarefa que se relaciona com a conscientização, ou seja, o desenvolvimento de uma consciência crítica com o fim de contribuir na compreensão daquilo que é intolerável e desumano na normalidade cotidiana imposta como natural (Martín-Baró, 1986).

Tal como foi definida aqui, a psicologia social deve possibilitar a liberdade social e individual. Se o objeto de estudo é a ação como ideológica, isto é, a ação determinada por fatores sociais vinculados aos interesses de classe dos diversos grupos, então busca-se a tomada de consciência desses determinismos pelo sujeito, quem pode se apropriar deles (aceitando-os ou recusando-os) por meio de uma práxis consequente. (Martín-Baró, 1985/2012, p. 48)

Assim, é papel da Psicologia Social desmascarar os interesses por trás das normas, regras sociais e ações humanas (Martín-Baró, 1985/2012; 1985/2017). Em outras palavras, cabe à Psicologia Social desvelar a ideologia da classe dominante, contribuir para a tomada de consciência dos determinismos da estrutura social e dos interesses de classe com fim de fomentar processos de libertação que se expressam nas práticas cotidianas (Martín-Baró, 1985/2012; 1985/2017). Para isso, desvendar os mecanismos ideológicos da violência é fundamental. Nesse sentido, trata-se de uma Psicologia Social que se coloca com a classe dominada, explicitamente comprometida com a transformação social.

\section{Ideologia e Violência}

A ideologia é produzida entre a estrutura objetiva e a estrutura subjetiva. Constitui-se como um mecanismo da classe dominante que atua nos aspectos cognitivos e afetivos, orientando tanto a interpretação como a atuação na realidade.

$\mathrm{Na}$ violência, a ideologia canaliza e expressa forças e interesses sociais nos conflitos que emergem da estrutura de classes e tende a ocultar as forças e interesses que a determina, sendo uma condição fundamental para a sustentação de relações violentas no cotidiano (Martín-Baró, 1988a/2017).

A ideologização da violência será destacada, neste trabalho, abordando sete processos que, claramente, demonstram a intrínseca articulação entre violência e ideologia no capitalismo: a) a difusão de uma concepção "neutra" de violência; b) a conversão da violência em uma questão técnica e administrativa; c) a desvalorização da vítima pela criação do “inimigo"; d) o acirramento da polarização social; e) a guerra psicológica que busca conquistar o envolvimento emocional das pessoas no conflito; f) o fatalismo como subproduto do sofrimento 
psíquico produzido pela violência estrutural; g) e a desatenção seletiva.

Em primeiro lugar, a ideologia atua na concepção, vigente tanto no senso comum quanto na psicologia hegemônica, que qualifica a violência como um fenômeno negativo a priori. Tal concepção oculta as forças e interesses sociais nos atos violentos porque, normalmente, somente se aplica aos atos que contrariam a ordem, enquanto todo ato necessário para a sustentação da ordem hegemônica segue sendo tomado como legítimo. A afirmação de que toda violência é negativa cria uma falsa aparência de neutralidade para a violência, ocultando os interesses de classes em disputa e converte a sua existência em uma questão moral (Martín-Baró, 1988a). Tal concepção moral patologiza as reações dos oprimidos às situações desumanizadoras que fortalecem as estruturas capitalistas. Quando o ordenamento social "não oferece alternativas mais eficazes do que a violência para alcançar seus propósitos" (MartínBaró, 1988a/2017, p. 300), a violência não é necessariamente desumanizante. De modo contraditório, a violência pode ser empregada justamente para romper com uma situação violenta, principalmente a violência estrutural, de forma a criar novas relações sociais que não se estruturam a partir do antagonismo entre classes. Assim, a violência também pode ser parte de um processo positivo e humanizador (Martín-Baró, 1985/2012).

A concepção "neutra" de violência é útil, por exemplo, para acobertar a violência exercida pelo Estado, tal como a violência policial. Esta é legitimada por ser uma violência advinda de uma autoridade legítima que exerce poder contra aqueles acusados de desrespeitarem a ordem. Por outro lado, a violência que se contrapõe à ordem (como a violência contra símbolos do capital praticada por Black Blocks) é vista como ilegítima por ser praticada por indivíduos deslegitimados pela classe dominante. Nesse contexto, para impedir o ato de violência "ilegítima", clama-se pela violência praticada pela "autoridade" legitimada pela classe dominante, como a violência policial. Nota-se nesse exemplo que o fundo ideológico é central, pois a violência praticada contra objetos (a violência de Black Blocks) é vista como menos legítima do que a violência praticada contra seres humanos (a violência policial ou a privação de condições dignas de vida).

Em segundo lugar, a ideologização da violência é facilitada pelo desmembramento da estrutura formal da violência, tal como ocorre na violência institucional, que converte a violência em uma questão meramente técnica e administrativa. Fundamentando-se nos estudos de Milgram sobre obediência à autoridade, Martín-Baró (1988a/2017) problematiza como delegar a responsabilidade pela violência a uma autoridade maior é um dos procedimentos que facilita a conversão do ato violento em ato técnico, facilitando, assim, a generalização das agressões violentas, inclusive aquelas caracterizadas pela crueldade.

A desindividualização do ato violento faz com que cada indivíduo execute parte da ação sem se sentir como um agente responsável pela violência. Cada sujeito efetiva uma porção da totalidade do ato, fazendo parecer que a responsabilidade pessoal se limite a assegurar a precisão técnica de parte do ato violento. Aqui, não existe nenhuma responsabilização pelos danos causados nas vítimas. Por este meio, a 
agressão sequer é vista como violência. Esta é reduzida à mera execução de uma ordem, tornando-se apenas mais uma atividade comum do trabalho (Martín-Baró, 1985/2012; 1988a/2017).

Em terceiro lugar, a criação de um inimigo é outro processo relevante na ideologização da violência. A legitimação ideológica da violência não ocorre somente pela justificação da ação do agente pelo poder estabelecido, mas também pela redução do status social da vítima, tornando mais fácil a aceitação do uso da violência contra ela (MartínBaró,1985/2012).

A “imagem do inimigo" é fundamental para prevenir a rebelião e o mal-estar entre os agentes responsáveis pela execução de atos violentos nas situações em que ela é usada como meio de sustentação da ordem. Quando o responsável pelo ato violento atribui valores negativos à vítima, um dos efeitos psicológicos pode ser o bem-estar e a autoimagem positiva - o que pode ocorrer também com expectadores que não se identificam com as vítimas. $\mathrm{O}$ elemento fundamental aqui é criar um distanciamento entre opressor que efetiva a violência e oprimido que é vítima, o que contribui para a naturalização da violência, convertendo-a em um hábito e em uma resposta privilegiada para a resolução de conflitos interpessoais e sociais (Martín-Baró, 1975).

O inimigo pode ser tomado como a fonte de frustrações sociais, sendo, assim, alvo da agressividade que poderia ser dirigida ao sistema que criou a frustração de expectativas sociais. Dessa forma, ações que, de outro modo não seriam aceitas, podem ser legitimadas. Atribuir ao inimigo uma valoração negativa, possibilita atribuir ao "nós" uma imagem positiva, inflando o valor próprio mesmo em condições desfavoráveis. O inimigo também justifica a criação e o fortalecimento de políticas repressivas e promove solidariedade e coesão interna em um grupo, facilitando, assim, a criação de uma identidade comum. Por fim, o inimigo é fundamental para fortalecer e configurar ideais de uma sociedade, criando uma cisão e diferenciação daqueles que se encaixam nesse ideal e dos que estão fora, isto é, uma diferença entre o "nós" e os “outros” (Martín-Baró, 1988a).

A criação do inimigo facilita a desumanização da vítima. Esta converte-se em mero elemento sem singularidade que pertence a um grupo, ou seja, é abstraído de individualidade e humanidade. Seu status social é despersonalizado, desvalorizado e demonizado. Usa-se adjetivos pejorativos tais como "bandidos", "baderneiros", "comunistas" e afins para criar um distanciamento entre o agredido e o expectador (Martín-Baró, 1987b/2017).

O "inimigo" facilita um quarto processo relacionado com a ideologia da violência: a polarização social. Esta só é possível pela divisão das pessoas em dois grupos: "nós", os bons, e "eles", os maus. Essa polarização cria um empobrecimento cognitivo nas análises dos agentes envolvidos nos conflitos sociais. Assim, a mente pode se estruturar em termos dicotômicos e simplórios, uma vez que as análises e respostas já estão dadas a priori: ao "outro" são atribuídos somente valores negativos, e ao "nós" são atribuídos valores absolutamente positivos (Martín-Baró, 1988b/2017).

Assim, a polarização explicita a assimetria na avaliação dos casos de violência: esta é injustificável quando vem do outro, sujeito absolutamente mal; enquanto o próprio 
comportamento jamais se constitui como um ato violento injustificável. Martín-Baró (1988a/2017) cita como exemplo o uso de minas terrestres como tática de combate: enquanto o exército de El Salvador denunciava e repudiava como uma grave violação aos direitos humanos a utilização de minas terrestres por "grupos terroristas", as mortes de guerrilheiros provocadas por minas eram celebradas como atos de heroísmo do exército.

Em conflitos sociais profundamente acirrados, tal como o que ocorreu em El Salvador, há também o desenvolvimento de uma forte guerra psicológica que busca conquistar as pessoas psicologicamente e emocionalmente. A guerra psicológica não é caracterizada pela diminuição dos atos "normais" de repressão violenta (buscar exterminar o inimigo, intensificação de políticas repressivas, produção de traumas psíquicos) empreendidos pelo Estado durante uma guerra, mas pela intensificação dos esforços que buscam envolver as pessoas afetivamente nos conflitos, facilitando comportamentos irracionais e a própria propagação de mentiras e manipulação (MartínBaró, 1987b/2017).

Assim, a "guerra psicológica" introduz a "institucionalização da calúnia”, isto é, a manipulação sobre os acontecimentos da guerra buscando heroicizar os atos empreendidos por "nós" e desprestigiar moralmente o "inimigo". Nesse processo, o controle sobre os meios de comunicação de massa é parte fundamental do conflito social (Martín-Baró, 1987b/2017).

O fatalismo é uma das possíveis configurações ideológicas que se manifestam entre os oprimidos pela violência estrutural. Se a resposta das vítimas da violência é a passividade, a vítima recai em um comportamento fatalista caracterizado como "um conformismo básico de grupos e pessoas com condições deploráveis de existência e com um regime opressor" (MartínBaró, 1989, p. 156).

O fatalismo é o processo pelo qual naturaliza-se uma realidade social infeliz, considerada como natural e insuperável. Tal naturalização só é possível a partir da redução do tempo histórico ao tempo presente, isto é, um presentismo determinista que nega a produção humana da história, delegando-a para outrem, geralmente uma entidade divina (Martín-Baró, 1987a/2017; 1989). Há, dessa forma, uma ideologização da realidade decorrente da violência cotidiana, que converte atividade e produção humana em forças excepcionais e exteriores à própria humanidade.

No fatalismo, o futuro é tomado como já predeterminado e inevitável, resta somente a submissão e a aceitação. Mesmo diante de situações deploráveis, opressoras e desumanas não há o que fazer, com exceção da submissão e da expectativa por uma salvação redentora. A passividade fatalista, ao não questionar e a naturalizar a ordem social, tende a bloquear todo esforço por transformação social e pessoal, contribuindo para a perpetuação da ordem imperante e, portanto, da violência estrutural (Martín-Baró, 1987a/2017; 1989).

O fatalismo não é fruto de ideias abstratas, mas é produzido e perpetuado a partir da própria realidade. As pessoas oprimidas ao perceberem que seus esforços na busca por mudar sua situação de opressão não transformam sua condição, tendem a naturalizar a ordem. Assim, as tentativas de transformação da realidade social são vistas de antemão como 
inúteis, desgastantes e por isso como algo que deve ser evitado. O fatalismo é, portanto, um correlato psíquico de estruturas sociais opressoras, isto é, de uma ordem social estruturalmente violenta (Martín-Baró, 1987a/2017).

Finalmente, um mecanismo ideológico relacionado com a dimensão ideológica da violência é a desatenção seletiva. Diante da impossibilidade de perceber todas as informações recebidas da realidade o ser humano desenvolveu mecanismos seletivos que contribuem para a percepção e o processamento das informações provenientes do entorno imediato. Quando percebemos determinadas informações, deixamos de assimilar outras. Tal seleção não se reduz apenas aos dados do ambiente imediato ou aos processos singulares e subjetivos. A percepção envolve o subjetivo, o percebido e o contexto social que estimula ou não determinadas percepções (Martín-Baró,1976; 1985/2012).

Nesse sentido, há dados que são facilmente recuperáveis e outros que são irrecuperáveis. Essa seleção não é aleatória e nem casual. Toda seleção de dados tem intencionalidade e causalidade. A desatenção seletiva contribui para a configuração do mundo pelo indivíduo. O que está em jogo não é a ausência de registro de dados do meio ambiente, mas sim para o fato de que o indivíduo não atenta para o seu significado e suas consequências. Os dados que não são percebidos pela desatenção seletiva não são irrelevantes, mas, pelo contrário, podem até ser de extrema relevância e, justamente por isso, o poder opressor tenta ocultar (MartínBaró, 1976).

A desatenção seletiva é uma atividade psíquica e pode ser um mecanismo de defesa do sujeito: se há dados que são ignorados sistematicamente é porque, inconscientemente, ao sujeito não interessa aprendê-los por provocar sofrimento. Quando se tem que realizar uma tarefa muito importante e difícil, o sujeito pode se esforçar para não apreender dados que afetam a execução das tarefas. Há uma seleção que contribui para evitar a angústia. $\mathrm{O}$ indivíduo, desse modo, protege-se, mantendo seu atual funcionamento e maneira de viver (MartínBaró,1976).

Martín-Baró (1976) apropria-se do conceito de filtro social de Erich Fromm para afirmar que há um mecanismo social e psíquico pelo qual se estabelece o que pode ser consciente e o que será relegado ao inconsciente em uma sociedade. A desatenção seletiva social mantém a sociedade tal como está. O significado da realidade social permanece ocultado e marginalizado, enquanto questões irrelevantes ou secundárias tornam-se centrais. "A atenção social seletiva não busca outra coisa: manter a atual ordem estabelecida. Não se ignoram os verdadeiros problemas políticos, mas ignoram-se seu significado político, comunitário, nacional. A mudança radical que eles demandam que é ignorada" (Martín-Baró, 1976, p. 109). Sendo assim, desaparece a perspectiva de transformação. $\mathrm{Na}$ relação entre desatenção social seletiva e violência, pode-se destacar como o primeiro processo contribui para que determinados elementos de uma ação violenta sejam percebidos e outros não. Da mesma forma, explica porque determinados comportamentos ou certas ações de violências são focadas em detrimento de outras. A desatenção social faz parte do próprio processo de ideologização da realidade. 


\section{Considerações Finais}

Ao afirmar que todo ato de violência tem um fundo ideológico, Martín-Baró explicita que todo ato de violência é histórico e decorrente das forças sociais que se desenvolvem no contexto da luta de classes. Ao trabalhar com tal perspectiva, o autor possibilita a apreensão de uma teia de relações sociais complexas na qual se insere a violência. Assim, analisar a violência exige analisar a sociedade e sua divisão em classes antagônicas, os interesses constitutivos dos atos violentos que, todavia, podem não ser aparentes durante a sua efetivação. Logo, a análise da violência vai para muito além do contexto imediato e da formalidade da ação, diferentemente das análises reducionistas das abordagens hegemônicas da Psicologia.

A historicização da violência somada à tentativa de uma análise em que convergem os aspectos estruturais e pessoais é certamente uma das maiores contribuições de Martín-Baró para compreender a violência e a ideologia e para pensar as tarefas da Psicologia na sociedade atual. É justamente a historicização da violência que coloca em relevo o tema da ideologia, processo pelo qual a estrutura social se internaliza.

Nos estudos de Martín-Baró, a ideologização da violência é um processo fundamental, pois é instrumental para a estruturação e a sustentação da sociedade capitalista. Assim, identificar os interesses ocultos nos diversos atos de violência é uma tarefa fundamental para a Psicologia Social. Nesse processo de desideologização é fundamental, também, a desnaturalização das violências, que se dão no cotidiano e a explicitação do possível potencial humanizador de atos violentos pelos oprimidos.
Contudo, apesar de tais contribuições, é possível identificar algumas limitações e problemas nas elaborações do autor. Em primeiro lugar, a definição, demasiadamente ampla, de violência torna possível identificar uma vastidão de comportamentos como violentos, sem diferenciar um do outro e qual seria o limite "aceitável" de força para definir um ato como violento. Entretanto, esse problema é parcialmente resolvido quando Martín-Baró descreve os aspectos específicos das diversas formas de violência.

Um problema importante parece existir na discussão sobre a ideologia. Há uma tensão entre uma concepção que, necessariamente, associa ideologia com mistificação e outra que toma a ideologia como dimensão constitutiva da ação por ela ser a mediação necessária na conversão de interesses sociais em experiências individuais. Assim, abre-se espaço para um importante debate que está presente, também, em toda a tradição marxista.

Outro problema que aparece nos estudos de Martín-Baró é a existência de, nos primeiros textos sobre violência (Martín-Baró, 1975; 1976), certo pragmatismo e ecletismo na adoção de diversas abordagens para o estudo da violência. $\mathrm{O}$ autor adota ideias e conceitos advindos, dentre várias abordagens, da Psicanálise, da Psicologia da Gestalt, da Psicologia Cognitiva e não atenta para possíveis contradições teóricas entre as diferentes correntes, deixando lacunas e criando dificuldades. Posteriormente, especialmente a partir de seu estudo crítico de Psicologia Social (Martín-Baró, 1985/2012), há uma clara tentativa de integrar e propor uma concepção de violência fundada em uma perspectiva histórica sob influência de ideias materialistas e dialéticas. 
É importante assinalar que é preciso reconhecer o contexto extremamente difícil em que a obra de Martín-Baró era desenvolvida. Ser alvo da violência estatal e conviver com a miséria produzida em uma sociedade capitalista dependente era algo que não apenas criava dificuldades, mas extenuava subjetivamente sua atividade - algo que o autor expressava em cartas (ver de la Corte, 2001). Assim, um sentido de urgência marcou uma obra que nunca se eximiu de interferir nos processos sociais que pretendia estudar.

A principal contribuição dos estudos psicossociais de Martín-Baró sobre violência é sua articulação entre violência e a ideologia. Ela é coerente com a preocupação do autor em contribuir para a desideologização da violência e da própria Psicologia.

A tarefa de desideologização é especialmente importante porque, para MartínBaró, a ideologia não é algo meramente externo à violência, mas é parte constitutiva. Por exemplo, o individualismo coloca as pessoas umas contra as outras; a propriedade privada faz com que as pessoas sejam avaliadas pelas suas posses, o que reforça as ações violentas para a consecução e manutenção dessas posses. Como a socialização dos indivíduos implica a apropriação das exigências do sistema imperante (ver o capítulo sobre socialização em Martín-Baró, 1985/2012), pode-se afirmar que há uma interiorização da violência estrutural, levando as pessoas a agirem de determinado modo - o que é um processo inerentemente ideológico relacionado com processos de opressão e alienação. Assim, a própria socialização é um mecanismo da violência estrutural.
Contudo, a internalização da ideologia e da violência não é algo insuperável. Com o avanço da consciência de classe, há a superação do individualismo, do fatalismo e uma mudança na própria percepção da violência e seus produtos, ocorrendo uma desideologização que resulta na compreensão da sociedade de um modo crítico, histórico e desnaturalizado, assumindo os próprios seres humanos como produtores da história. Quando isso ocorre e quando há uma organização da classe trabalhadora, os alicerces da sociedade capitalista são questionados, acirrando a luta de classes.

Assim, por meio da violência, o capitalismo se funda e só por meio da violência ele é capaz de se manter. A ideologia é fundamental nesse processo por justificar e proliferar o comportamento violento necessário para a manutenção da ordem capitalista, fazendoo parecer necessário para o bem da sociedade quando na verdade só o é para a classe dominante - de modo que a desideologização é fundamental para a superação da sociedade capitalista e é precisamente pela desideologização que a Psicologia Social pode contribuir para processos de transformação social.

\section{Referências}

Blanco, A. (1998). La coherencia en los compromisos. In A. Blanco (Org.). Ignacio Martin-Baró: Psicología de la liberación (pp. 936). Madrid: Editorial Trotta.

Blanco, A., \& de la Corte, L. (2003). Psicología social de la violencia: la perspectiva de Ignacio Martín-Baró. In A. Blanco \& L. de la Corte (Orgs.). Poder, ideología y violencia (pp. 9-62). Madrid: Editorial Trotta. 
De la Corte, L. (2001). Memoria de un compromiso: La psicología social de Ignacio Martín-Baró. Bilbao: Desclée de Brouwer.

Dantas, B. S. do A. (2015). Contribuições teóricas ao estudo psicopolítico da ideologia. Teoría y Crítica de la Psicología, 5, 77-101.

Dobles, I. (2016). Ignacio Martín-Baró: Una lectura en tiempos de quiebres y esperanzas. San José: Editorial Alerkín.

Fernandes, F. (2009). Capitalismo dependente e classes sociais na América Latina (4a ed.). São Paulo: Global.

Lessa, S. (2014). Lukács, trabalho e classes sociais. In G. Costa e N. Alcântara (Orgs.). Anuário Lukács 2014 (pp. 255). São Paulo: Instituto Lukács.

Martín-Baró, I. (1975). El valor psicológico de la represión política mediante la violencia. Estudios Centroamericanos, 30(326), 742-752.

Martín-Baró, I. (1976) La desatención social del poder opresor. In I. Martín-Baró (Org.). Problemas de Psicología Social (pp. 98-109). San Salvador: UCA Editores.

Martín-Baró, I. (1980/2017). O psicólogo no processo revolucionário (F. Lacerda Jr. Trad.). In F. Lacerda Jr. (Org.). Crítica e libertação na Psicologia: Estudos psicossociais (pp. 25-29). Petrópolis: Vozes.

Martín-Baró, I. (1985/2017). A desideologização como contribuição da psicologia social para o desenvolvimento da democracia na América Latina (F. Lacerda Jr. Trad.). In F. Lacerda Jr. (Org.). Crítica e libertação na Psicologia: Estudos psicossociais (pp. 5565). Petrópolis: Vozes.

Martín-Baró, I. (1985/2012). Acción y ideología: Psicología Social desde Centroamérica (2a ed.). San Salvador: UCA Editores.

Martín-Baró, I. (1986). Psicología social desde Centroamérica: retos e perspectivas
(Entrevista com o Dr. Ignacio MartínBaró cedida a Ignacio Dobles). Revista Costarricense de Psicología, 8-9, 71-76.

Martín-Baró, I. (1987a/2017). O latino indolente (F. Lacerda Jr. Trad.). In F. Lacerda Jr. (Org.). Crítica e libertação na Psicologia: Estudos psicossociais (pp. 173-203). Petrópolis: Vozes.

Martín-Baró (1987b/2017). Da guerra suja à guerra psicológica: o caso de El Salvador (F. Lacerda Jr. Trad.). In F. Lacerda Jr. (Org.). Crítica e libertação na Psicologia: Estudos psicossociais (pp. 271-285). Petrópolis: Vozes.

Martín-Baró, I. (1988a/2017). A violência na América Central: uma visão psicossocial (F. Lacerda Jr. Trad.). In F. Lacerda Jr. (Org.). Crítica e libertação na Psicologia: Estudos psicossociais (pp. 286-311). Petrópolis: Vozes.

Martín-Baró, I. (1988b). A violência política e a guerra como causas do trauma psicossocial em El Salvador (F. Lacerda Jr. Trad.). In F. Lacerda Jr. (Org.). Crítica e libertação na Psicologia: Estudos psicossociais (pp. 312-332). Petrópolis: Vozes.

Martín-Baró, I. (1989). Sistema, grupo y poder: Psicología Social desde Centroamérica II. San Salvador: UCA Editores.

Martins, K. O., \& Lacerda Jr., F. (2014). A contribuição de Martín-Baró para o estudo da violência: uma apresentação. Revista Psicologia Política, 14(31), 579-589.

Netto, J. P., \& Braz, M. (2006). Economia política: uma introdução crítica (5a ed.). São Paulo: Cortez.

Sloan, T. (2015). Una carta a Ignacio con respecto a la tarea de la desideologización. Teoría y Crítica de la Psicología, 5, 06-11.

Recebido em: 13/02/2017 
Aprovado em: 10/03/2018 